\title{
CONCEPTUALISATION OF THE THERAPEUTIC ALLIANCE IN PHYSIOTHERAPY: IS IT ADEQUATE?
}

\section{Introduction}

Over the last decade physiotherapy practice has undergone a paradigm shift towards a biopsychosocial (BPS) model of care (Smith, 2002). This contrasts a traditional biomedical, or therapist-centred approach (Josephson, Woodward-Kron, Delany, \& Hiller, 2015; O'Sullivan, 2012). This shift has been encouraged by governing bodies (CSP, 2011), academics and clinicians (Engel, 1997; McCollum \& Pincus, 2009). Subsequently a rhetoric of concepts such as person-centred practice and the therapeutic alliance (TA) has emerged.

The TA is recognised as an integral aspect of care amongst allied health care professionals (Elvins \& Green, 2008; Lambert \& Barley, 2001) and has recently received increased focus in physiotherapy research. Studies suggest a strong TA has an association with improved physiotherapy outcomes (Ferreira et al., 2013; Fuentes et al., 2014; Kinney et al., 2018). Limited evidence exists however regarding its conceptual meaning and influence in physiotherapy practice (Babatunde, MacDermid, \& MacIntyre, 2017; Taccolini Manzoni, Bastos de Oliveira, Nunes Cabral, \& Aquaroni Ricci, 2018). The concept of alliance originates from Freud's theory of transference and countertransference, whilst its characterisation was perhaps first discussed by Rogers (1965), profiling the importance of the person's experience of therapists empathetic approach (Rogers, 1965).

Within physiotherapy practice Bordin's (1979) tripartite definition of the Working Alliance (WA) is currently most widely utilised. Conceived within psychotherapy practice, the definition does not encompass central physiotherapy-specific facets of the care such as therapeutic touch, manual therapy or exercise. Thus, its applicability towards physiotherapy practice may be limited. 
Many concepts of care exist within healthcare. These can be viewed as representations, or building blocks of existing theory (Rodgers \& Knafl, 2000). Theoretical concepts are brought to life through operationalisation as they are reformatted towards the relevant clinical context, a process influenced by sociocultural and professional background (Kerry, Maddocks, \& Mumford, 2008; Shaw \& DeForge, 2012). Although there has been an increase in physiotherapy literature concerning the TA, no agreement exists regarding the TAs conceptual understanding and its subsequent operationalisation or influence on outcomes (Besley, Kayes, \& McPherson, 2011; Taccolini Manzoni et al., 2018). Recent systematic reviews have called for conceptual clarity of the TA concept in order to include the TA as an independent variable within research (Hall, Ferreira, Maher, Latimer, \& Ferreira, 2010; Lakke \& Meerman, 2016; Taccolini Manzoni et al., 2018). It is therefore the aim of the present concept analysis to seek conceptual clarity of the TA concept within physiotherapy literature.

\section{Methodology}

\section{Concepts}

Concepts can be considered mental constructions created to organise our environmental stimuli (Walker \& Avant, 1995), and so must contain categories of information which in turn enclose their defining attributes. Conceptual understanding is influenced by one's ontological ${ }^{1}$ and epistemological ${ }^{2}$ position and may be construed as the characteristics and attributes enabling an individual to conceptualise an idea in different contexts.

\section{Concept Analysis:}

A concept analysis strives to provide conceptual clarification, commonly through identification and meaning of words (Baldwin \& Rose, 2009; Rodgers \& Knafl, 2000). Failure to clearly articulate concepts' definition and attributes may lead to impaired

\footnotetext{
${ }^{1}$ Ontology: the study of being, or the nature of reality. Knowledge that exist externally to the individual

${ }^{2}$ Epistemology: the study of knowledge external to the individual, concerns itself with the nature of knowing
} 
operationalisation, and confuse its intellectual understanding (Rodgers, 1989). An evolutionary approach to concept analysis was used for this study (Rodgers \& Knafl, 2000), forming a contemporary view of concepts. It adopts a constructivist ${ }^{3}$ perspective as part of an inductive approach (Rodgers \& Knafl, 2000; Tofthagen \& Fagerstrøm, 2010).

\section{Methods}

This study followed a 'concept analysis' methodology. The evolutionary approach to concept analysis used follows 5 steps (Figure 1) (Rodgers \& Knafl, 2000). Steps 1 and 2 relate to the methods, whilst step 3 bridges the methods and data analysis. For the purposes of this article the remaining steps of the evolutionary approach will be presented in the relevant journal article sections.

Figure 1: Evolutionary method of concept analysis within a traditional qualitative research framework

\footnotetext{
${ }^{3}$ Constructivism: The means of acquiring knowledge from own experiences and one's ideas.
} 


\section{Traditional qualitative research methodology}

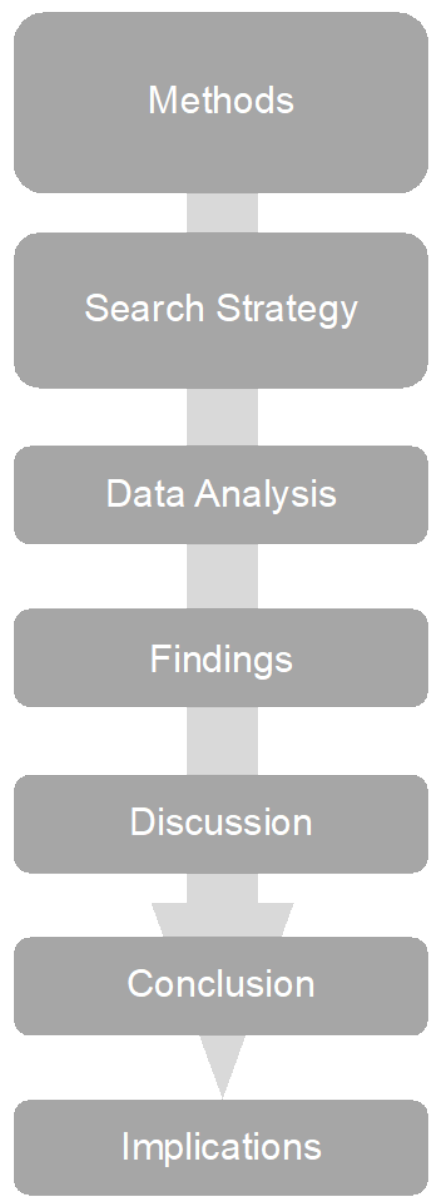

\section{Evolutionary method of Concept Analysis}

1. Identify concept of choice and surrogate terms

2. Select appropriate setting and sample for data collection.

3. Data collection through literature search. Identify antecedents, attributes and consequences.

4. Analyse data for each area and compare similarities (themes) and dissimilarities.

5. Reveal the analysis implication, hypothesis and direction of further concept development

1. Identify concept of choice and surrogate (associated) terms

2. Select appropriate setting and sample for data collection

3. Data collection through a literature search (methods). Identify attributes, antecedents and consequences (analysis).

1. Identify concept of choice and surrogate (associated) terms

The TA concept within physiotherapy practice was selected. Preliminary searches of the 'Therapeutic Alliance' AND 'Physiotherapy' through Pubmed and AMED databases revealed surrogate terms linked with the concept (Table 1). Surrogate terms are alternative words which express the ideas of a concept and formed part of the literature search strategy based on frequency of occurrence and contextual relevance to the TA. This ensured a wider and more applicable search. 
Table 1: Surrogate terms "therapeutic allian*"/ "therapeutic relation*" / "patient-centered*" / "patient-centred*" / "person-centered" / "person-centred*" / "patient-therapist collaboration*" / "persontherapist collaboration*" / "work*-allianc*" / "work*-relation*" / bond / "helping allianc*" / physiotherap* / "physical therap*" /rehabilitation

\section{Select appropriate setting and sample for data collection}

Following the initial preliminary search, a comprehensive database search was conducted covering; Pubmed, MEDLINE via Ovid, AMED, CINAHL Plus, Cochrane, Psych Info and Embase via Ovid databases. The search was carried out utilising the listed surrogate terms (Table 1) in combination with 'Physiotherapy' and 'Therapeutic Alliance'. Additional application of Boolean operators 'AND' and 'OR' with truncations $\left({ }^{*}\right)$ and (") were utilised.

Table 2: Search strategy

("therapeutic allian*" OR "therapeutic relation*" OR "patient-centered*" OR "patientcentred" OR "person-centered" OR "person-centred" OR "patient-therapist collaboration*" OR "person-therapist collaboration*" OR "work*-allianc*" OR "work*relation*" OR bond OR "helping allianc*") AND (physiotherap* OR "physical therap*") AND (rehabilitation)

A systematic search of the literature was subsequently carried out. No restrictions were applied to the year of publication as no prior concept analysis of the TA within physiotherapy practice was identified. This suggested a wide scope of the evidence base would be suitable. Titles and abstracts were screened (by PS) against inclusion criteria. In the event of uncertainty of conceptual clarity and study eligibility, studies were reviewed by GDK and $\mathrm{CH}$ for clarification.

Table 3: Inclusion criteria applied towards potential articles:

Peer reviewed literature

No year restriction to publication applied

Articles conceptually discuss the therapeutic alliance within a physiotherapy context

Literature published in Norwegian or English language 
Figure 2: Flowchart outlining literature search and study selection

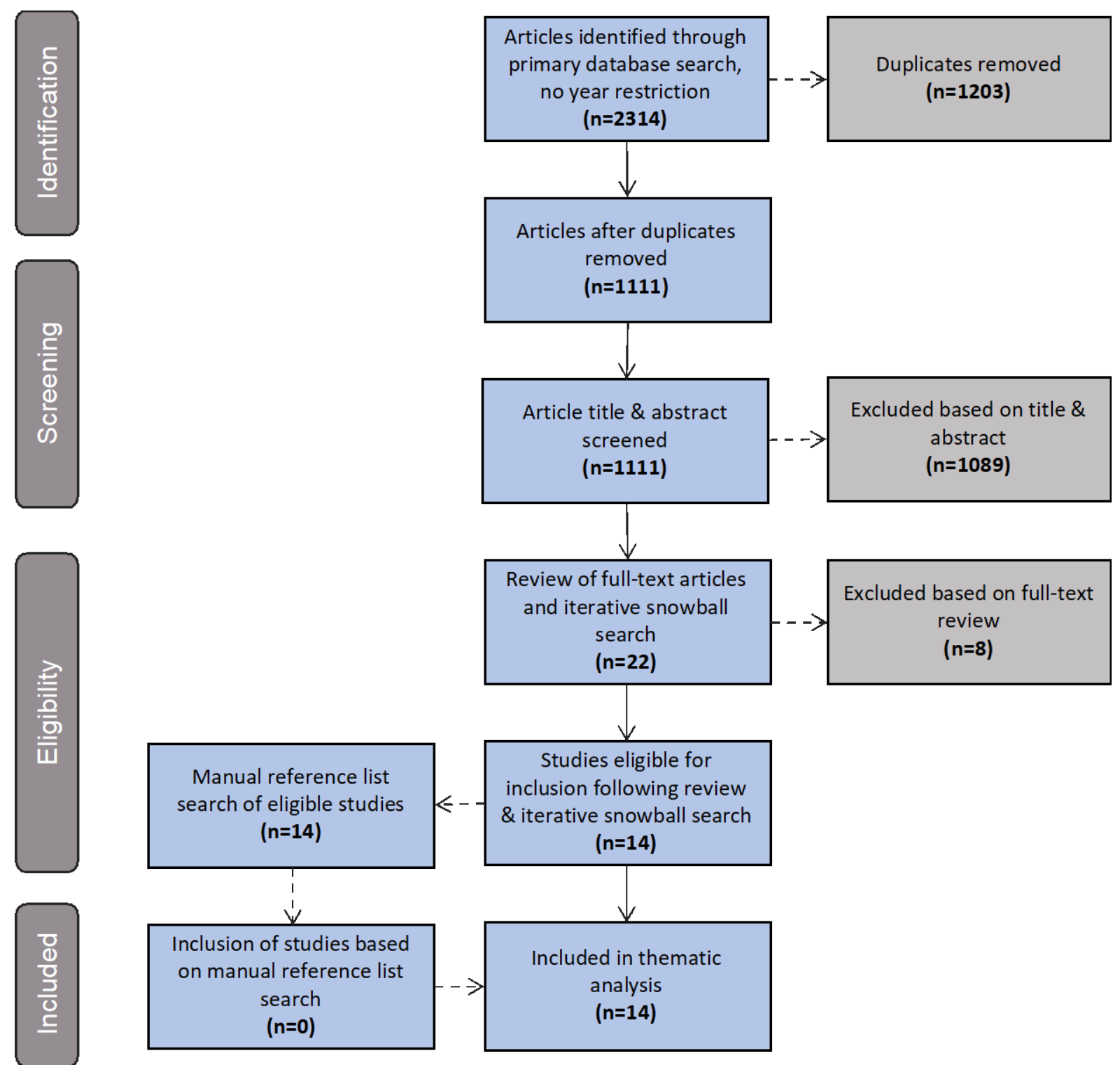

(Moher, Liberati, Tetzlaff, \& Altman, 2009)

3. Data collection through a literature search. Identify attributes, surrogate terms, antecedents and consequences

The literature search sought to identify conceptual antecedents, attributes and consequences relating to the TA. Conceptual antecedents describe events or phenomena which precede the concept. Attributes are characteristics which describe the concept at hand and provide its conceptual definition. Conceptual consequences 
describe the resulting events that may occur as a result of the concept (Walker \& Avant, 2005).

\section{Data Analysis}

Fourteen studies (Appendix 1) were selected for inclusion into the thematic analysis. The analysis phase contains steps 4 and 5 of the evolutionary concept analysis approach, and was conducted via inductive, semantic thematic analysis following Braun and Clarke's 6-step guide (Table 4) (Braun \& Clarke, 2006). The data was systematically searched, and it was deemed that data saturation was achieved prior to proceeding with the data analysis process.

Steps 4 and 5 of a concept analysis are sectioned within the data analysis as listed below:

4. Analyse data for each area and compare similarities (themes) and dissimilarities

5. Reveal the analysis implications and direction of further concept development.

Table 4: Braun and Clarke's guide to Thematic Analysis

\begin{tabular}{|ll|}
\hline 1. & Familiarise yourself with the data \\
\hline 2. & Generating initial codes \\
\hline 3. & Searching for themes within the identified codes \\
\hline 4. & Reviewing themes \\
\hline 5. & Defining and naming themes \\
\hline 6. & Providing the report \\
\hline
\end{tabular}

4. Analyse data for each area and compare similarities (themes) and dissimilarities

It was not the purpose of the analysis to quality assess the included studies, consequently no quality appraisal was conducted. The focus of the analysis of the included studies remained on their conceptual discussion of the TA within a physiotherapy context. 
A hermeneutic approach was applied and sought to discern and explore the inherent meaning within the data. Its application enabled consideration of individual components within the larger context, the TA (Heidegger, 1962). Step 4 of the concept analysis compares similarities (themes) and dissimilarities within the data. This was conducted through the first author's interpretivist, realist and rationalist lens, however all three authors worked in close co-operation during the data analysis process. Visual representations of the conceptual attributes were provided (Figures 3-7). The attribute themes act as master themes in outlining the concepts underlying characteristics. Step 5 highlights how the analysis findings may influence future discussions and conceptual development within the physiotherapy profession.

\section{Findings}

In line with concept analysis methodology, the antecedent, master attribute and consequence themes, and sub-themes found within the data corpus are presented (Appendix 1-4).

\section{Antecedent themes relating to the concept}

The following antecedent themes were identified in the literature and are considered below.

1. 'Paradigm shift'

2. 'Evolving evidence, but stagnant implementation' Sub-theme: 'Early education'

3. 'Lack of guidance'

\section{Paradigm shift}

'Paradigm shift' highlighted the ongoing change within healthcare philosophy, transitioning from a BMM to a BPSM within physiotherapy practice. The need for a multifactorial approach in clinical practice was outlined (Crepeau, 2016; A. L. Gyllensten, Gard, Salford, \& Ekdahl, 1999; Harman, Bassett, Fenety, \& Hoens, 2012; Morera-Balaguer, Botella-Rico, Martinez-Gonzalez, Medina-Mirapeix, \& Rodriguez-Nogueira, 2018; Tasker, Loftus, \& Higgs, 2012; Wilson, Chaloner, 
Osborn, \& Gilbert, 2017), with emphasis on greater equality within the therapeutic relationship (TR) (Bellner, 1999; Gartland, 1984; Harman, MacRae, Vallis, \& Bassett, 2014; Miciak, Mayan, Brown, Joyce, \& Gross, 2018a; Wilson et al., 2017).

\section{Evolving evidence, but stagnant implementation}

'Evolving evidence, but stagnant implementation' outline how physiotherapists felt supported by the growing body of evidence concerning establishing a strong TA and adopting a person-centred approach within the therapeutic encounter (Gartland, 1984). Conceptual discussions suggested a strong TA may lead to improved therapeutic outcomes.

The literature however, highlighted a lack of consensus concerning the conceptual underpinnings of the TA (Hall et al., 2012). A call for conceptual clarity within the clinical context was raised (Gartland, 1984; Kayes \& McPherson, 2012; Gyllensten, Hansson, \& Ekdahl, 2003; Miciak et al., 2018a; Tasker et al., 2012).

\section{Sub-theme: Early education}

The need for early education within a BPSM framework in undergraduate and postgraduate physiotherapy education was highlighted (Brun-Cottan, McMillian, \& Hastings, 2018). It was suggested that increased focus on communication, interdisciplinary collaboration and behaviour change techniques could assist physiotherapists in creating strong TA's (Gartland, 1984; Harman, Bassett, Fenety, \& Hoens, 2012; Harman et al., 2014; Wilson et al., 2017).

\section{Lack of guidance}

The lack of operational guidance was stated to be a key component of physiotherapists failing to establish a strong TA (Brun-Cottan et al., 2018; Miciak et al., 2018a; Miciak, Mayan, Brown, Joyce, \& Gross, 2018b), and a divide existed within the profession concerning physiotherapists' role within the therapeutic encounter (Bellner, 1999; Harman et al., 2014).

\section{Master attribute themes relating to the concept}


The master attribute themes, and sub-themes identified during the thematic analysis are outlined (Figures 3-7).

1. 'Seeing the person'

Sub-theme: 'Giving of self'

2. 'Sharing the journey'

Sub-theme: 'Legitimising the experience'

3. 'Communication'

4. 'Therapeutic space'

Sub-theme: 'Physiotherapist characteristics matter'

5. 'Fostering autonomy'

Sub-theme: 'Interpersonal collaboration'

\section{Seeing the person}

Figure 3: Conceptual attributes constituting 'Seeing the person' theme, and subtheme 'Giving of self'. The large circle depicts the master attribute theme, whilst the smaller circles represent the attribute codes. The attribute codes act as building blocks to form the master theme. The smaller circle on the right represents the subtheme and its respective attribute codes.

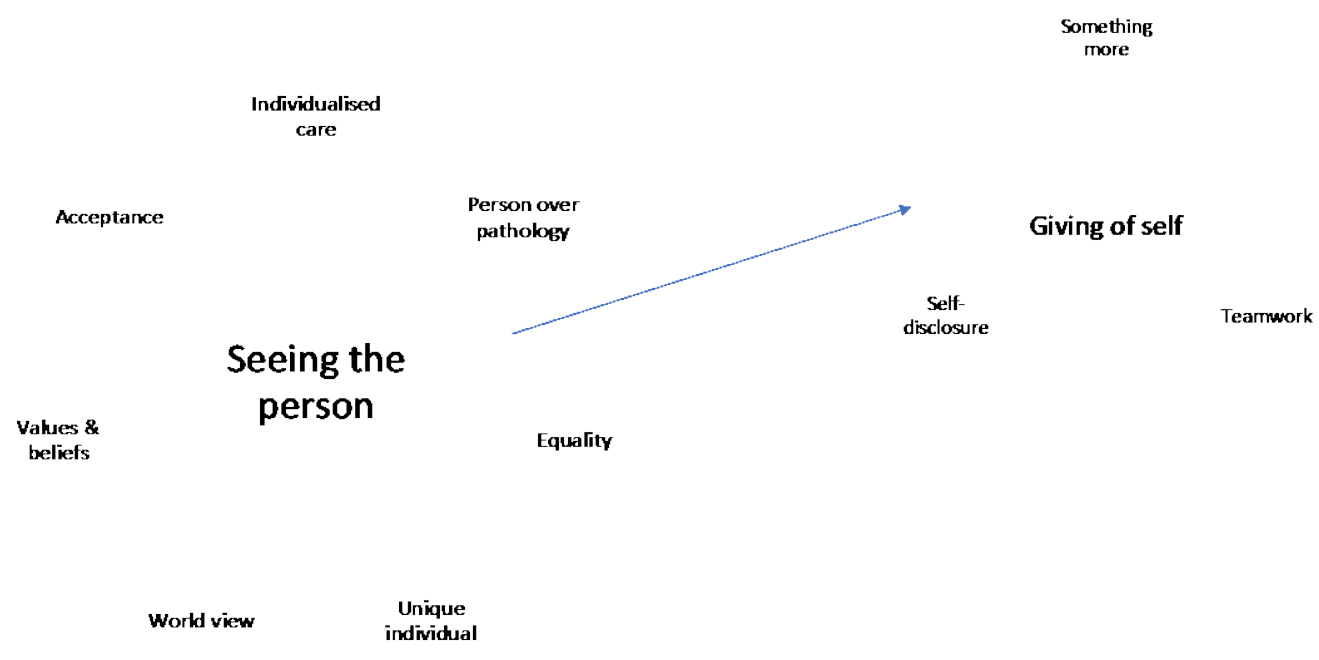


The literature described the importance of physiotherapists attention to the individual within the clinical encounter. Discussions focused on learning personal characteristics, values, beliefs, and demonstrating acceptance of their unique world view in establishing connections (Bellner, 1999; Crepeau, 2016; Gyllensten et al., 1999; Gyllensten et al., 2003; Miciak et al., 2018a). This could allow physiotherapists to provide bespoke care, and meeting their expectations, seeing the person rather the pathology (Kayes \& McPherson, 2012; Wilson et al., 2017; Brun-Cottan et al., 2018). The following quotation portrays a patient's experience and perception of when a physiotherapist enquires about their lived experience of pain:

“... it was a bit like, oh my God, they are asking me how I am and they are talking about feelings... This isn't quite right. But it was lovely, really refreshing to have that kind of. Because they are interested in your physical and mental well-being, it's the two things" (Wilson et al., 2017, p.101).

\section{Sub-theme: Giving of self}

Physiotherapists' role in creating a connection and understanding the person seeking care, involved sharing of themselves. Authors suggested it was the physiotherapists' duty in initiating a connection and developing a TA through selfdisclosure (Crepeau, 2016; Miciak et al., 2018a, 2018b; Wilson et al., 2017). This facilitated reciprocity within the alliance, facilitating a sense of teamwork, developing the TA into 'something more' than just a person-physiotherapist interaction (Kayes \& McPherson, 2012; Wilson et al., 2017). 


\section{Sharing the journey}

Figure 4: Conceptual attributes constituting 'Sharing the journey' theme, and subtheme 'Legitimising the experience'.

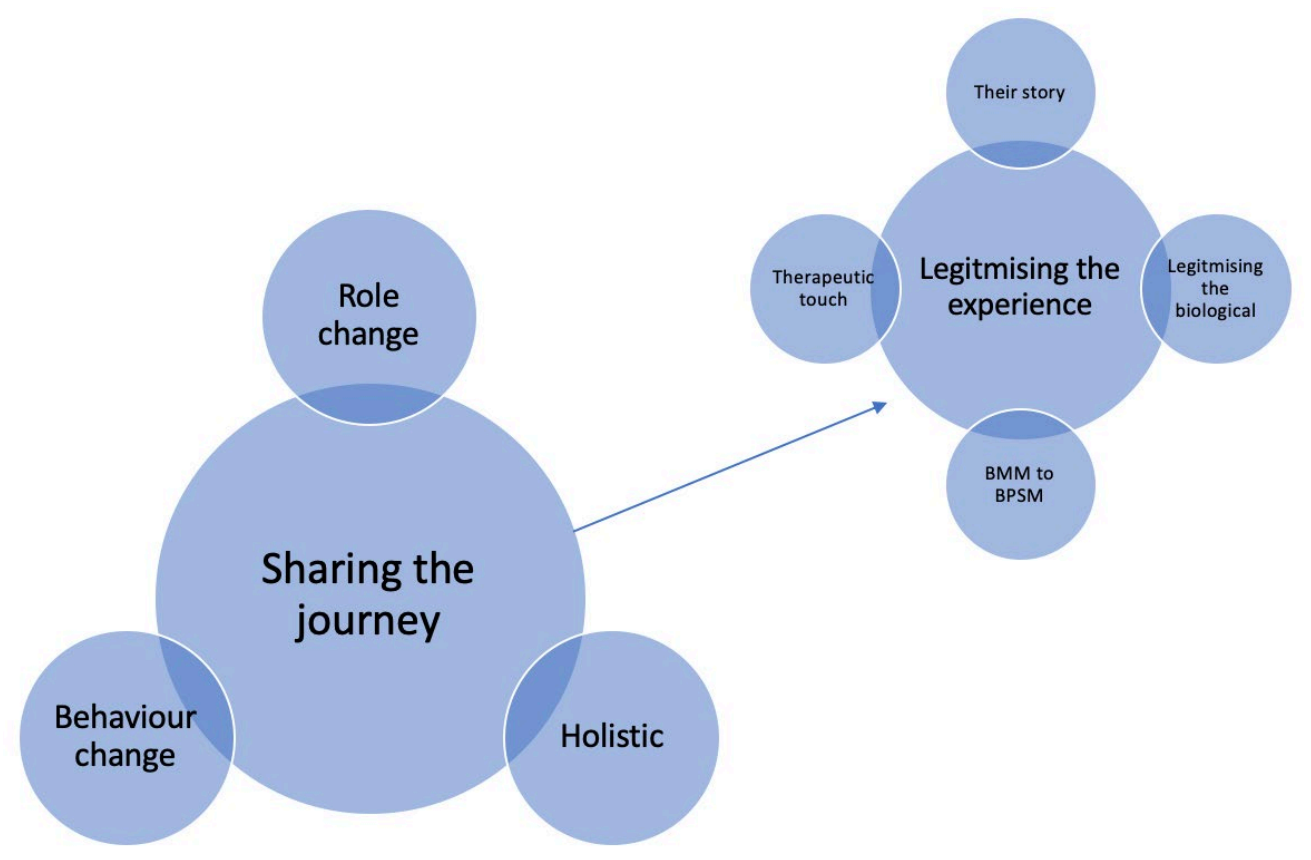

The authors described the perceived importance of physiotherapists sharing the therapeutic journey with people seeking care, in assisting the person from being dependent to independent (Bellner, 1999; Harman et al., 2014; Miciak, et al., 2018b). Physiotherapists dynamic role-change along the persons journey from expert to "fellow travellers", mirroring the organic development of the alliance was highlighted (Brun-Cottan et al., 2018; Tasker et al., 2012). Behaviour change was viewed as treatment progression, with the person seen to obtain greater awareness and control over own problems. This was linked with successful therapeutic outcomes (Harman et al., 2014). The following patient quotation illustrates a relationship-centred approach.

“...she just took an interest and so genuine you know... Yes, from the outset, she was really interested in me" (Tasker et al., 2012, p.9). 


\section{Sub-theme: Legitimising the experience}

Those receiving care highlighted the need for their experience to be legitimised by physiotherapists, in particular the biological beliefs (Bellner, 1999; Crepeau, 2016; Miciak et al., 2018a). It was proposed that utilising the person's story and interpretation of their own condition could be a "way in" for additional exploration of their presentation (Gyllensten et al., 1999; Miciak et al., 2018a). Therapeutic touch could function as a medium in legitimising someone's pain experience and reconceptualising a person's movement. This could act as a foundation of establishing a physical and emotional connection (Miciak et al., 2018b).

\section{Communication}

Figure 5: Conceptual attributes constituting 'Communication' theme.

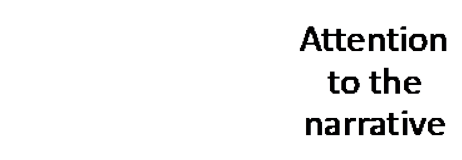

Language $\begin{gathered}\text { Verbal } \\ \text { and non- } \\ \text { verbal }\end{gathered}$


narrative was to feel listened to, implemented through active listening (Gyllensten et al., 1999).

"the quality of health care hinges ultimately on the quality of interaction within the therapeutic relationship" (Gartland, 1984, p.25).

Authors suggested effective communication enabled physiotherapists' to create a positive first impression and stimulate reflective thinking (Brun-Cottan et al., 2018). This relief on physiotherapists ability to identify and respond appropriately to verbal and non-verbal communication. For instance, touch could function as tactile communication and be perceived as a caring and an empathetic expression from the physiotherapist (Harman et al., 2012). An empathetic manner was perceived when demonstrating an awareness of the person's emotional state and feelings (Gartland, 1984; Miciak et al., 2018a, 2018b).

\section{Therapeutic space}

Figure 6: Conceptual attributes constituting 'Therapeutic space' theme, and subtheme 'Physiotherapist characteristics matter'.

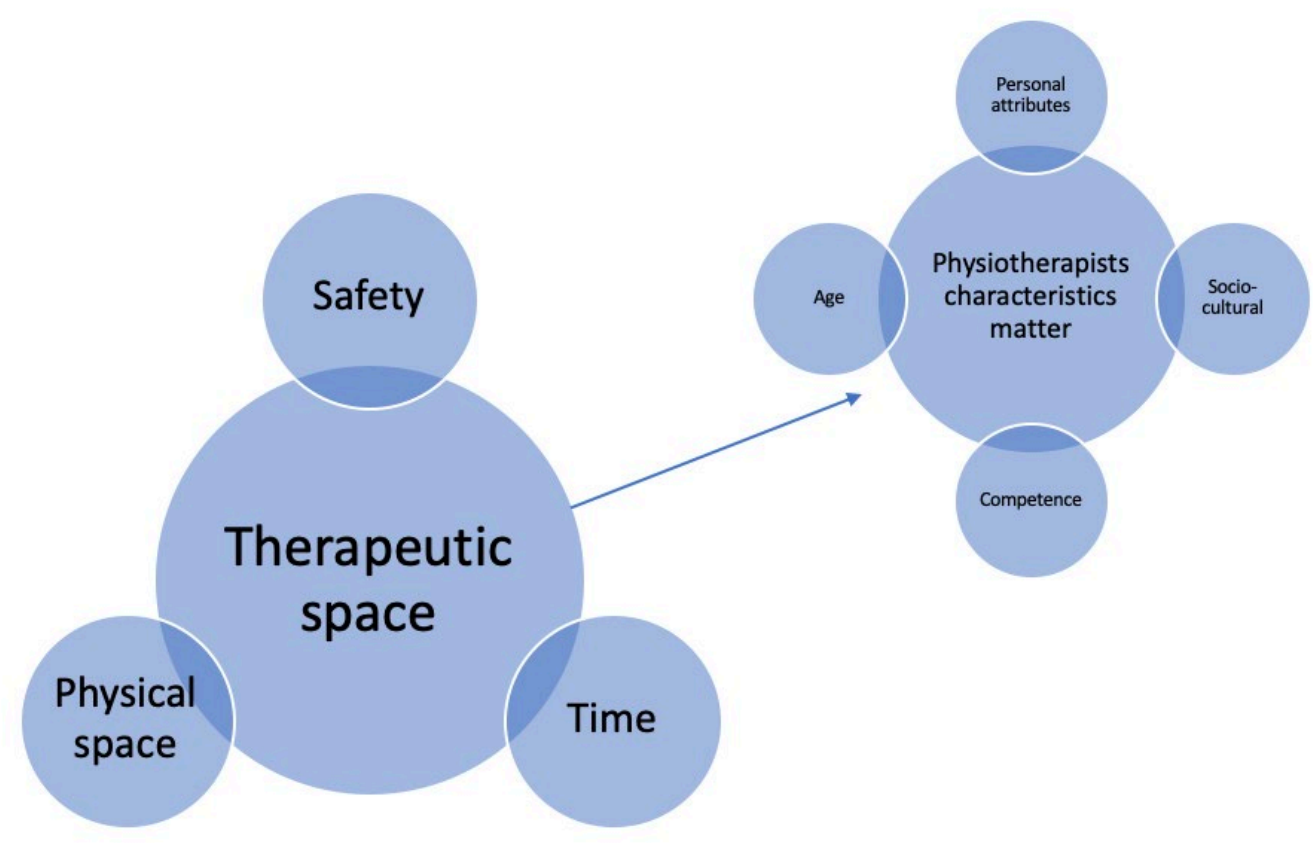


The sense of safety people felt within the therapeutic space was outlined as allowing patients to unfold themselves physically and psychologically (Miciak et al., 2018b; Wilson et al., 2017).

"Both the amount of available resources and the environment you have been exposed to, have an influence on you" (Gyllensten et al., 1999, p.97).

Safety could be created by physical space allowing privacy enhancing a sense of intimacy within the TA, also allowing people to open up about feelings and emotions relating to their condition (Harman et al., 2012; Morera-Balaguer et al., 2018). Both physiotherapists and those receiving care valued space and time within the encounter, whilst time limitations could inhibit developing the TA (Brun-Cottan et al., 2018; Gartland, 1984; Wilson et al., 2017).

\section{Sub-theme: Physiotherapists characteristics matter}

Authors noted physiotherapists' age and physical appearance could trigger subconscious bias regarding level of competence or experience (Gartland, 1984; Harman et al., 2012; Morera-Balaguer et al., 2018). Additionally, sociocultural background could influence both physiotherapists and people's ability to connect and establish an alliance. Personal attributes could influence the TA, outlining physiotherapists ability to demonstrate willingness to help, coming across empathetic and genuine (Gyllensten et al., 1999). Attributes of kindness, empathy, confidence, positivity, humour and security in self were valued in physiotherapists (Gyllensten et al., 2003). 


\section{Fostering autonomy}

Figure 7: Mind map of attributes constituting 'Fostering autonomy' theme, and subtheme 'Interpersonal collaboration'.

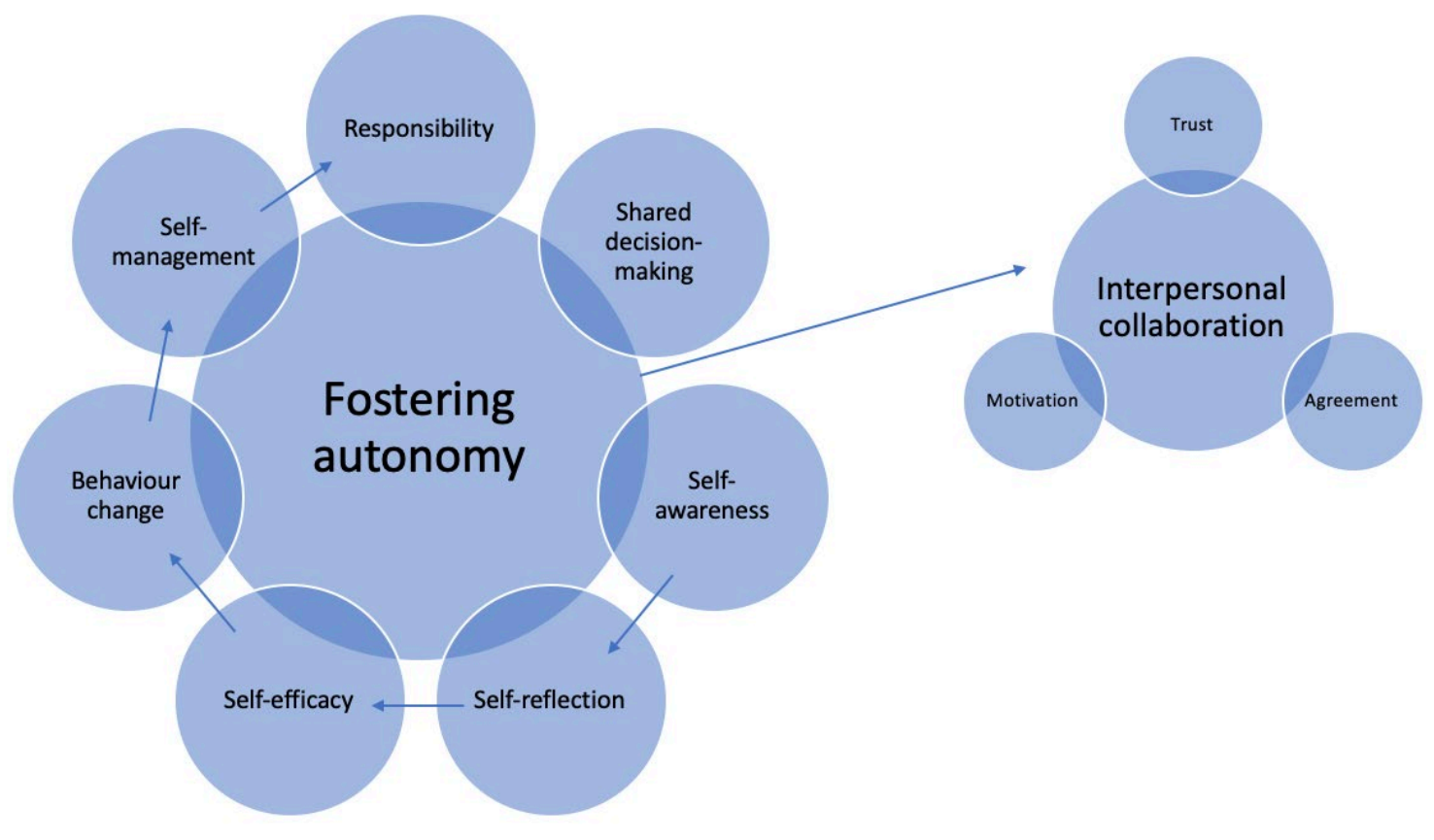

Autonomy was described as a journey a person underwent throughout the therapeutic process, encompassing learning about oneself, demonstrating acceptance towards one's position and deciding to change one's outlook on future events, acting towards a more independent future (Crepeau, 2016; Gartland, 1984; Gyllensten et al., 1999). The theme was described by interlinking attributes reflecting the continuum of autonomy; increased 'self-awareness', 'self-reflection', 'selfefficacy', leading to 'behaviour change' and enhanced 'self-management' (Bellner, 1999; Harman et al., 2012; Miciak et al., 2018a; Morera-Balaguer et al., 2018; Wilson et al., 2017)

The below quote illustrates the challenges patients face in developing selfawareness regarding their condition.

"I guess sometimes it could be realising that actually you've missed out on so much" (Wilson et al., 2017, p.102).

The literature outlined the process of gaining autonomy as regaining independence over their own circumstances, freeing oneself from the dependence of seeking care (Harman et al., 2014). It reflected the change in values and beliefs of the person, 
affirming an incentive for sustained independent self-management (Bellner, 1999; Gartland, 1984; Gyllensten et al., 1999; Kayes \& McPherson, 2012; Miciak et al., $2018 b)$. Central in the autonomy continuum was the role of shared decision-making, reflective of equality within the alliance (Crepeau, 2016; Gyllensten et al., 2003; Miciak et al., 2018a; Brun-Cottan et al., 2018).

\section{Sub-theme: Interpersonal collaboration}

Authors outlined effective change and regained autonomy of own circumstances relied on a supportive environment and motivation for change. Interpersonal collaboration built on agreement on goal between physiotherapist and the person (Brun-Cottan et al., 2018; Miciak et al., 2018a). Reciprocal trust within the alliance underlined the belief and trust people had in their physiotherapist (Crepeau, 2016; Morera-Balaguer et al., 2018).

\section{Consequence themes relating to the concept}

The following consequenxe themes were identified following thematic analysis.

1. 'Improving therapeutic outcomes'

2. 'Continual educational needs'

3. 'Sharing responsibilities'

Sub-theme: 'A shift to person-centred focus'

4. 'Enhanced clarity'

\section{Improving therapeutic outcomes}

The literature suggested physiotherapists should value the TA as a facilitator of improved therapeutic outcomes, and that the TA should be emphasised within educational institutions, enhancing physiotherapists' awareness of the TA within clinical practice (Gartland, 1984; Gyllensten et al., 1999; Miciak et al., 2018a; Morera-Balaguer et al., 2018).

\section{Continual educational needs}

Authors suggested teaching of the TA and interpersonal relationships should be prioritised early in undergraduate and postgraduate curriculums through clinical 
mentorships and reinforced in practice-based settings (Gartland, 1984; Gyllensten et al., 1999). Emphasis should be placed on communication skills (Morera-Balaguer et al., 2018), and on context specific behaviour strategies in creating connections within a person-centred approach (Miciak et al., 2018a; Wilson et al., 2017).

\section{Sharing responsibilities}

It was suggested that physiotherapists initiated and facilitated the establishment of connections and subsequent TA's (Miciak et al., 2018a, 2018b). However, the success of the TA and improved therapeutic outcomes also relied on collaborative efforts in achieving agreed therapeutic goals (Miciak et al., 2018b; Tasker et al., 2012).

\section{Sub-theme: a shift to a person-centred focus}

Literature outlined the underlying paradigm shift in healthcare philosophy, transitioning the therapeutic encounter from therapist- to person-centred, aligning with clinical guidelines (Bellner, 1999; Gyllensten et al., 1999; Morera-Balaguer et al., 2018; Wilson et al., 2017).

\section{Enhanced clarity}

The literature outlines the lack of clarity concerning the TA, as well as a lack of operational guidelines in how to best establish and maintain a strong TA (Miciak et al., 2018a). The increased frequency of publications surrounding the TA is gradually raising awareness of the TA and reconceptualisation is needed to clarify clinical application (Kayes \& McPherson, 2012; Miciak et al., 2018b; Wilson et al., 2017).

\section{Discussion}

As healthcare philosophy has transitioned from a BMM towards a BPSM model of care, reflective of the antecedent 'Paradigm shift', authors have discussed the gradual implementation of a pluralistic ${ }^{4}$ reasoning framework (Wilson et al., 2017).

\footnotetext{
${ }^{4}$ Pluralism: Belief in differences, supporting diversity and that different substances contribute towards reality
} 
Calls for a more holistic approach in treating people with multifactorial presentations have been made, incorporating more adaptive reasoning, inclusive of the person's social and psychological world (Harman et al., 2014; Lewis \& O'Sullivan, 2018; Tasker et al., 2012). Moreover, it was suggested that increased awareness amongst physiotherapists own epistemological stance was necessary to enhance awareness around this paradigm shift and implementation of such change (Bientzle, Cress, \& Kimmerle, 2014; Kerry et al., 2008).

Figure 8: Venn diagram illustrating Bordin's (1979) tripartite definition of the WA

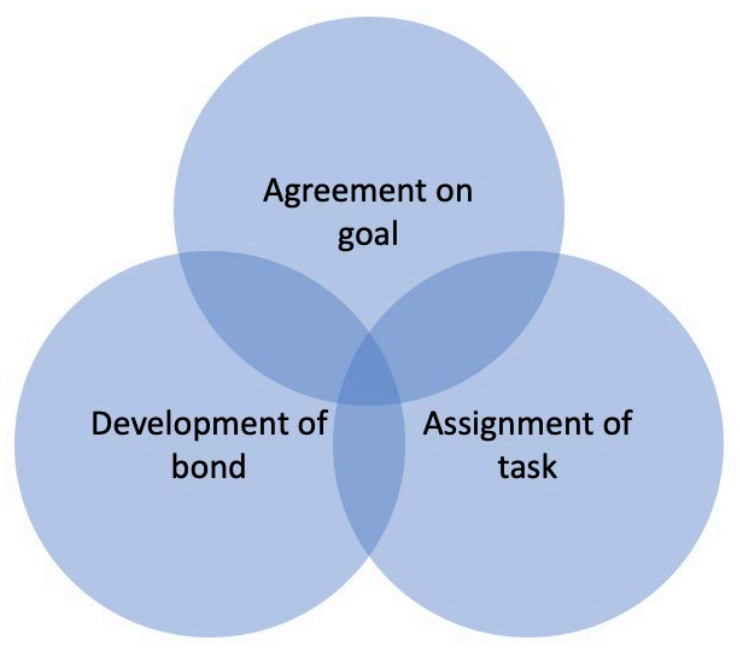

The conceptualisation of the TA as outlined within the master attribute themes share similarities with Bordin's conceptualisation (1979). Inherent within both conceptualisations is the person at the centre, but differences exist. Firstly, Bordin's tripartite definition is mirrored in much of the current conceptual analysis. The role of 'agreement on goal' can be found within the 'Fostering autonomy' and 'Sharing the journey' themes. Whilst Bordin emphasised the importance of mutuality within the act of goal-setting, he largely referred to the person identifying their own dysfunctions in form of stresses, frustrations and the dissatisfactions associated with their own way of thinking, acting and feeling (Bordin, 1979). The present conceptualisation emphasised a higher degree of equality, shared narratives and collaborative efforts during goal setting. Thus, reciprocity was a central attribute and both physiotherapist and patient contributed equally (Bellner, 1999; Crepeau, 2016; Kayes \& McPherson, 2012). This reflected the 'Seeing the person' theme, where physiotherapists accepted the individual within the encounter based on their values and beliefs, and 
acknowledged their world-view and focused care on the person rather than the pathology (Miciak et al., 2018a).

Secondly, Bordin discussed the 'assignment of task' as collaboration on an agreedupon contract between the person and the therapist. He formulated the assignment as therapist-driven, with little mention of person-centredness within the encounter (Bordin, 1979). Parallels can be drawn to a therapist-centred approach, and although agreement between therapist and person was seen concerning the intervention or treatment goal, the act of implementing this into practice relied heavily on the therapist, rendering the person a receiver of care (Smith, 2002). This conceptualisation viewed the operationalisation of task, or the implementation of therapeutic intervention as a graded approach (Harman et al., 2014). This reflected the development of the TA, although commonly initiated by the therapist, reciprocity remained central to maintaining and developing the TA further (Miciak et al., 2018a, 2018b). TA, within a physiotherapy context appears to align more closely with Donabedian's (1966) work on the role of the therapeutic journey and inclusion of equal collaboration throughout the therapeutic process. Bordin (1979) highlighted central attributes reflected within a physiotherapy-driven conceptualisation; empathetic understanding, communication, interpretation and self-disclosure (Bordin, 1979). These attributes align with the sub-theme 'Giving of self', and the 'Seeing the person' theme (Crepeau, 2016; Amanda Lundvik Gyllensten, Hansson, \& Ekdahl, 2003; Miciak et al., 2018a, 2018b; Wilson et al., 2017). Additionally, 'Communication' was strongly placed within this context as the key to operationalise therapy techniques.

Communication in the context of the TA may function as the vehicle to apply the theoretical framework into practice. It heavily featured throughout the data corpus as the means of negotiation and including of the person within the TA, whilst the person utilised communication in their own right to influence the TA from their position, underlining its bilateral nature (Crepeau, 2016; Harman et al., 2014; Miciak et al., 2018a).

The final facet of Bordin's conceptualisation of the TA discussed the development of the bond between person and therapist. Its relationship as Bordin described it, reflect 
the wider TA construct as the therapist was referred to as friend or coach (Bordin, 1979). Bordin suggested time as a key factor in developing the bond, in contrast to the 'Therapeutic space' theme, where authors outlined the importance of first impressions and precognitions as facilitating and inhibiting development of the TA (Morera-Balaguer et al., 2018).

Central in a physiotherapy conceptualisation of the TA are attributes specific to the profession. The 'Therapeutic touch' attribute separates a physiotherapy- and psychotherapy-driven conceptualisation, as did 'Legitimising the biological', acknowledging a person's belief regarding their condition and facilitating development of their understanding towards contemporary knowledge. This opened up for change (Harman et al., 2014) and proved central to the transition from the initial connection seen early within an alliance (Miciak et al., 2018a), and operationalising the alliance within therapeutic intervention. Embedded within the 'Therapeutic touch' was the use of manual application or facilitation, also described as 'hands on'. It was perceived as a means of "bridging the gap", in the aim of returning confidence to the person (Harman et al., 2012; Miciak et al., 2018a).

By bringing together the interlinking attribute themes, one can begin to see the whole emerging through the parts. Stronger direction is provided towards the ambiguous concept of the TA within physiotherapy literature, supported by a proposed model of implementation advanced from Bordin's conceptualisation of the WA. A conceptual interpretation of the TA is visually presented (Figure 9) with emphasis placed on removing barriers between the interlinking attributes demonstrating its dynamic features. It illustrates a continuous TA, with attribute themes merging together to form the TA, emphasising the importance of communication within education and operationalisation of the TA (Gartland, 1984; Gyllensten et al., 1999; Harman et al., 2012; Wilson et al., 2017). Communication is portrayed centrally as a catalyst within the circular model corresponding with the hermeneutic circle; without the part, one cannot see the whole. 
Figure 9: A conceptual model of the TA attributes. highlighting 'Communication' as a key catalyst towards operationalisation within the clinical encounter

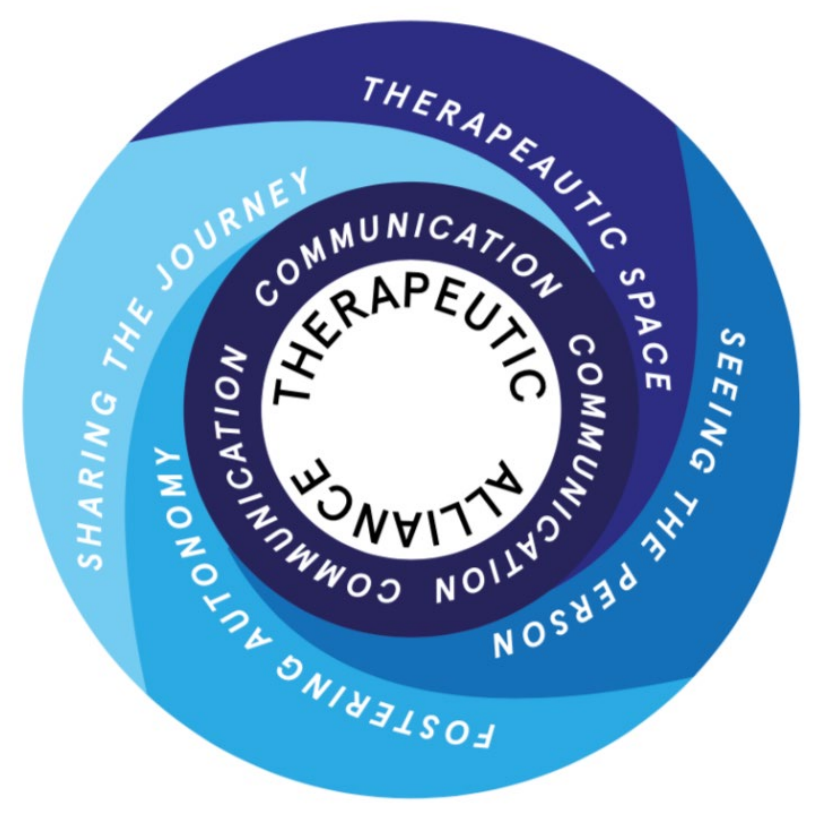

\section{Limitations}

Primary data analysis was conducted by a musculoskeletal physiotherapist. Themes developed throughout the analysis process may be biased towards this area of physiotherapy practice. The use of the hermeneutic circle and reflexivity were utilised to ensure the analysis was data driven.

Concept analysis stage 5. Reveal the analysis implication, hypothesis and direction of further concept development

As the final stage in a concept analysis this section aims to outline how the presented analysis findings and discussion may influence future physiotherapy practice and research.

This is the first concept analysis looking at the TA within physiotherapy practice. It offers a contemporary view of the TA within physiotherapy literature, and provides the reader with the opportunity to conceptualise the TA within their own ontology 
(Rodgers \& Knafl, 2000). Further concept development is needed, and the authors hope others will repeat this concept analysis, providing "the next layer" of conceptualisation. This concept analysis provides a plausible operational framework when considering the TA construct within their clinical practice.

\section{Conclusion}

A new model of interpreting and operationalising the TA concept is presented, incorporating attributes physiotherapist can influence. Additional conceptual development within physiotherapy is needed, as this concept analysis adds depth to the current understanding of the TA within physiotherapy literature and may offer greater operational clarity for physiotherapists within their context-driven epistemologies.

\section{Declaration of interest}

The authors declare no conflict of interest. 


\section{$\underline{\text { References }}$}

Babatunde, F., MacDermid, J., \& MacIntyre, N. (2017). Characteristics of therapeutic alliance in musculoskeletal physiotherapy and occupational therapy practice: a scoping review of the literature. BMC Health Serv Res, 17(1), 375. doi:10.1186/s12913-017-2311-3

Baldwin, M. A., \& Rose, P. (2009). Concept analysis as a dissertation methodology. Nurse Educ Today, 29(7), 780-783. doi:10.1016/j.nedt.2009.03.009

Bellner, A. L. (1999). Senses of responsibility: a challenge for occupational and physical therapists in the context of ongoing professionalization. Scandinavian Journal of Caring Sciences, 13(1), 55-62.

Besley, J., Kayes, N. M., \& McPherson, K. M. (2011). Assessing Therapeutic Relationships in Physiotherapy: Literature Review. New Zealand Journal of Physiotherapy, 39(2).

Bientzle, M., Cress, U., \& Kimmerle, J. (2014). Epistemological beliefs and therapeutic health concepts of physiotherapy students and professionals. BMC Med Educ, 14, 208. doi:10.1186/1472-6920-14-208

Bordin, E. S. (1979). The generalizability of the psychoanalytic concept of the working alliance. Psychotherapy: Theory, research \& practice, 16(3), 252.

Braun, V., \& Clarke, V. (2006). Using thematic analysis in psychology. Qualitative research in psychology, 3(2), 77-101.

Brun-Cottan, N., McMillian, D., \& Hastings, J. (2018). Defending the art of physical therapy: Expanding inquiry and crafting culture in support of therapeutic alliance. Physiother Theory Pract, 1-10. doi:10.1080/09593985.2018.1492656

CSP (2011): Code of members' professional values and behaviour. Chartered Society of Physiotherapy (UK). Available at: https://www.csp.org.uk/publications/code-members-professional-values-andbehaviour (Accessed on 12.08.2018).

Crepeau, E. B. (2016). "I need someone to keep an eye on me:" the power of attention in patient-practitioner interactions. Disability \& Rehabilitation, 38(24), 2419-2427. doi:10.3109/09638288.2015.1129443 
Elvins, R., \& Green, J. (2008). The conceptualization and measurement of therapeutic alliance: An empirical review. Clinical psychology review, 28(7), 1167-1187.

Engel, G. L. (1997). From biomedical to biopsychosocial: Being scientific in the human domain. Psychosomatics, 38(6), 521-528.

Ferreira, P. H., Ferreira, M. L., Maher, C. G., Refshauge, K. M., Latimer, J., \& Adams, R. D. (2013). The therapeutic alliance between clinicians and patients predicts outcome in chronic low back pain. Phys Ther, 93(4), 470-478. doi:10.2522/ptj.20120137

Fuentes, J., Armijo-Olivo, S., Funabashi, M., Miciak, M., Dick, B., Warren, S., . . . Gross, D. P. (2014). Enhanced therapeutic alliance modulates pain intensity and muscle pain sensitivity in patients with chronic low back pain: an experimental controlled study. Physical therapy, 94(4), 477-489.

Gartland, G. J. (1984). Teaching the therapeutic relationship. Physiotherapy Canada, 36(1), 24-28.

Gyllensten, A. L., Gard, G., Salford, E., \& Ekdahl, C. (1999). Interaction between patient and physiotherapist: a qualitative study reflecting the physiotherapist's perspective. Physiother Res Int, 4(2), 89-109.

Gyllensten, A. L., Hansson, L., \& Ekdahl, C. (2003). Patient experiences of basic body awareness therapy and the relationship with the physiotherapist. Journal of Bodywork and movement therapies, 7(3), 173-183.

Hall, A. M., Ferreira, M. L., Clemson, L., Ferreira, P., Latimer, J., \& Maher, C. G. (2012). Assessment of the therapeutic alliance in physical rehabilitation: a RASCH analysis. Disabil Rehabil, 34(3), 257-266.

doi:10.3109/09638288.2011.606344

Hall, A. M., Ferreira, P. H., Maher, C. G., Latimer, J., \& Ferreira, M. L. (2010). The influence of the therapist-patient relationship on treatment outcome in physical rehabilitation: a systematic review. Phys Ther, 90(8), 1099-1110. doi:10.2522/ptj.20090245

Harman, K., Bassett, R., Fenety, A., \& Hoens, A. M. (2012). Client Education: Communicative Interaction between Physiotherapists and Clients with Subacute Low Back Pain in Private Practice. Physiother Can, 63(2), 212-223. doi:10.3138/ptc.2009-52P 
Harman, K., MacRae, M., Vallis, M., \& Bassett, R. (2014). Working with people to make changes a behavioural change approach used in chronic low back pain rehabilitation. Physiotherapy Canada, 66(1), 82-90.

Heidegger, M. (1962). Being and time (J. Macquarrie \& E. Robinson, trans.). In: New York: Harper \& Row.

Josephson, I., Woodward-Kron, R., Delany, C., \& Hiller, A. (2015). Evaluative language in physiotherapy practice: How does it contribute to the therapeutic relationship? Soc Sci Med, 143, 128-136.

doi:10.1016/j.socscimed.2015.08.038

Kerry, R., Maddocks, M., \& Mumford, S. (2008). Philosophy of science and physiotherapy: an insight into practice. Physiother Theory Pract, 24(6), 397407. doi:10.1080/09593980802511797

Kinney, M., Seider, J., Beaty, A. F., Coughlin, K., Dyal, M., \& Clewley, D. (2018). The impact of therapeutic alliance in physical therapy for chronic musculoskeletal pain: A systematic review of the literature. Physiother Theory Pract, 1-13. doi:10.1080/09593985.2018.1516015

Lakke, S. E., \& Meerman, S. (2016). Does working alliance have an influence on pain and physical functioning in patients with chronic musculoskeletal pain; a systematic review. Journal of Compassionate Health Care, 3(1), 1.

Lambert, M. J., \& Barley, D. E. (2001). Research summary on the therapeutic relationship and psychotherapy outcome. Psychotherapy: Theory, research, practice, training, 38(4), 357.

Lewis, J., \& O'Sullivan, P. (2018). Is it time to reframe how we care for people with non-traumatic musculoskeletal pain? In: BMJ Publishing Group Ltd and British Association of Sport and Exercise Medicine.

McCollum, L., \& Pincus, T. (2009). A biopsychosocial model to complement a biomedical model: patient questionnaire data and socioeconomic status usually are more significant than laboratory tests and imaging studies in prognosis of rheumatoid arthritis. Rheum Dis Clin North Am, 35(4), 699-712, v. doi:10.1016/j.rdc.2009.10.003

Miciak, M., Mayan, M., Brown, C., Joyce, A. S., \& Gross, D. P. (2018a). A framework for establishing connections in physiotherapy practice. Physiother Theory Pract, 1-17. doi:10.1080/09593985.2018.1434707 
Miciak, M., Mayan, M., Brown, C., Joyce, A. S., \& Gross, D. P. (2018b). The necessary conditions of engagement for the therapeutic relationship in physiotherapy: an interpretive description study. Arch Physiother, 8, 3. doi:10.1186/s40945-018-0044-1

Moher, D., Liberati, A., Tetzlaff, J., \& Altman, D. G. (2009). Preferred reporting items for systematic reviews and meta-analyses: the PRISMA statement. Annals of internal medicine, 151(4), 264-269.

Morera-Balaguer, J., Botella-Rico, J. M., Martinez-Gonzalez, M. C., MedinaMirapeix, F., \& Rodriguez-Nogueira, O. (2018). Physical therapists' perceptions and experiences about barriers and facilitators of therapeutic patient-centred relationships during outpatient rehabilitation: a qualitative study. Brazilian Journal of Physical Therapy, 18, 18.

O'Sullivan, P. (2012). It's time for change with the management of non-specific chronic low back pain. Br J Sports Med, 46(4), 224-227. doi:10.1136/bjsm.2010.081638

Rodgers, B. L. (1989). Concepts, analysis and the development of nursing knowledge: the evolutionary cycle. Journal of advanced nursing, 14(4), 330335.

Rodgers, B. L., \& Knafl, K. A. (2000). Concept development in nursing: Foundations, techniques, and applications: Saunders Philadelphia, PA.

Rogers, C. R. (1965). The therapeutic relationship: Recent theory and research. Australian Journal of Psychology, 17(2), 95-108.

Shaw, J. A., \& DeForge, R. T. (2012). Physiotherapy as bricolage: theorizing expert practice. Physiother Theory Pract, 28(6), 420-427. doi:10.3109/09593985.2012.676941

Smith, R. C. (2002). The Biopsychosocial Revolution: Interviewing and Providerpatient Relationships Becoming Key Issues for Primary Care. Journal of general internal medicine, 17(4), 309-310.

Taccolini Manzoni, A. C., Bastos de Oliveira, N. T., Nunes Cabral, C. M., \& Aquaroni Ricci, N. (2018). The role of the therapeutic alliance on pain relief in musculoskeletal rehabilitation: A systematic review. Physiother Theory Pract, 1-15. doi:10.1080/09593985.2018.1431343 
Tasker, D., Loftus, S., \& Higgs, J. (2012). Head, heart and hands: Creating mindful dialogues in community-based physiotherapy. New Zealand Journal of Physiotherapy, 40(1), 5-12.

Tofthagen, R., \& Fagerstrøm, L. M. (2010). Rodgers' evolutionary concept analysis-a valid method for developing knowledge in nursing science. Scand J Caring Sci, 24 Suppl 1, 21-31. doi:10.1111/j.1471-6712.2010.00845.x

Walker, L., \& Avant, K. (1995). Strategy for theory construction in nursing. Connecticut: Appleton-Century Crofts.

Walker, L., \& Avant, K. (2005). Theory analysis. Strategies for theory construction in nursing, 160-179.

Wilson, S., Chaloner, N., Osborn, M., \& Gilbert, J. G. (2017). Psychologically informed physiotherapy for chronic pain: patient experiences of treatment and therapeutic process. Physiotherapy, 103(1), 98-105.

doi:10.1016/j.physio.2015.11.005 
